\title{
Strangers in a foreign land — developing cultural closure criteria for mines in Australia's Northern Territory
}

\author{
H.D. Smith Northern Land Council, Australia
}

\begin{abstract}
The Northern Land Council is a statutory body created under the Aboriginal Land Rights Act (1976) to protect the rights and interests of traditional Aboriginal landowners. An important part of this work requires the Land Council to deal with appropriate restoration of leased Aboriginal lands following cessation of industrial projects such as mining. This paper seeks to demonstrate that cultural, as well as ecological matters can and should be addressed at closure.
\end{abstract}

Using an example from the Arnhem Land region of Australia's Northern Territory, it is shown that cultural information is an important factor that can be integrated into the mine site rehabilitation and closure process during the planning phase. When archaeological and anthropological records are supplemented with extant traditional cultural knowledge, it is possible to develop a cultural landscape, or map, that defines locations of special significance. If the location of the mine and its sphere of impacts is referenced against this map specific work required to redress cultural impacts can be undertaken.

It is found that by focussing on the physical attributes, ecology and keystone cultural species for each culturally important location, micromanagement of this part of the rehabilitation process is required. This requires links between cultural and ecological knowledge to be defined if the overall cultural integrity of the landscape is to be reconstructed. Outcomes are dependent upon the quality of information that can be recovered, the willingness of traditional custodians to discuss its importance and the extent of damage that has been done.

\section{Introduction}

Australia's Northern Territory contains one of the world's largest known belts of high-grade uranium mineralisation, stretching over $300 \mathrm{~km}$ from Pine Creek in the south to beyond the now closed Nabarlek Mine in the north. Three world class deposits covered by the Ranger, Jabiluka and Koongara mineral leases are located in a unique environment, surrounded by World Heritage listed Kakadu National Park to the north, south and west; and by Aboriginal freehold land to the east. Of these, Ranger is the only operating mine, and this is currently scheduled for closure by 2021, although there are now indications that mining will progress well into the future. Yet, despite having been in operations for over 30 years, work has only now begun on planning for closure.

The Northern Territory's uranium belt and Kakadu National Park are also home to a large population of Aboriginal Australians who continue to maintain and practise a living cultural heritage that is known to have continued for tens of thousands of years. Important cultural sites such as Malakanundja II, which has been dated to 60,000 years before present, are dotted throughout the Kakadu landscape and attest to this extreme span of cultural activity. In comparison, Ranger uranium mine has been operating for a mere 30 years, but has had a devastating effect on cultural practices previously undertaken on the area of land now consumed by the mining lease.

At the start of mining, the Commonwealth of Australia issued a set of environmental requirements which have since been reviewed (DEWHA, 1999) and which the operators of the mine must meet before a closure certificate can be issued. These requirements are specific to Ranger Mine, and although they are rather ambiguous and vague they do provide a somewhat flexible guide for rehabilitation. At the core of these is the requirement to rehabilitate the mining lease and operational area to a standard commensurate with surrounding landscape, so that the rehabilitated areas may be successfully integrated into Kakadu National Park. 
Recently, considerable effort has been placed into planning a post-mining landform and functional ecosystem (EWL Sciences Pty Ltd, 2006), but work on cultural attributes has so far been limited mainly because the necessary expertise does not seem to exist and because necessary ongoing consultation with Aboriginal people have not been held. Instead, the major focus has been placed on using analogue landscapes (Hollingsworth and Lowry, 2005) and models (Hancock et al., 2000) to define a final landform. The biggest problem with this approach is that the analogues selected may allow the return of a functional ecology; it may not be one that fully reflects lost cultural values, nor produce a satisfactory replacement for the rich cultural landscape that has been damaged. The detail required to address cultural components can only be derived through the express involvement of the customary Aboriginal land owners who are the creators and the owners of the cultural landscape.

Since 2003, the Northern Land Council has worked with the mine's operators and with the Binin land owners to develop programmes that recognise and formalise the role that traditional ecological knowledge plays in development of closure criteria required to address the ecological attributes of the environmental requirements (Glen and Smith, 2006). This has been identified and touched upon in a previous paper (Smith, 2008), and is now slowly being incorporated into closure plans for the mine. However, traditional ecological knowledge is only one part of the cultural landscape. Cultural landscapes are defined as cultural properties that represent the "combined works of nature and man". They are illustrative of the evolution of human society and settlement over time, under the influence of the physical constraints and/or opportunities presented by their natural environment and of successive social, economic, and cultural forces (UNESCO, 2008). In Kakadu, the cultural landscape continues to reflect Binin living tradition, even though on the Ranger lease it has been damaged by the destructive forces of mining.

Efforts so far to define the final landform exemplify the Eurocentric philosophy of a reductionist approach that attempts to deal with the environment in parts and then attempts to 'glue' these parts together. This approach will not work well with a cultural landscape, which requires a more holistic approach. Links between spirituality, society, culture and traditional ecological knowledge need to be determined and taken into account during landform reconstruction if the commonwealth's environmental requirements are to be met fully and the land returned to a state fit for inclusion into Kakadu National Park. One possible approach, which would satisfy the requirements of the land owners, the commonwealth government and the World Heritage Commission, is to determine pre-mining cultural attributes from an analysis of the cultural and physical landscapes that existed thirty or more years ago.

This paper describes recent work that has been undertaken by the Northern Land Council and the owners of the land affected by the mine, community Mirarr Gundjeihmi, to define the pre-mining cultural attributes of the land. Here, traditional cultural knowledge has been supplemented by historical, archaeological and anthropological records and from this an understanding of the cultural landscape of the mining lease area in the context of the surrounding Kakadu National Park has been developed. Further work will be undertaken over the next few years to clearly define areas of more specific cultural activity that have been affected by operations in the immediate vicinity of the mine.

\section{Methods}

Federal, territory and mining company archives were searched to identify anthropological and archaeological material related to historic cultural activity on the Ranger mining lease. This was followed by formal participatory consultation with senior members of the Mirarr Gundjeihmi community to elucidate extant knowledge of cultural uses of the affected and adjacent lands, and to compare this with retrieved records. The information was collated, and notes made of any significant variations for later investigation and/or clarification.

Following consultation, a number of cultural walks were undertaken with participation of Mirarr Gundjeihmi. These followed ancient walking trails leading to a number of important cultural sites (such as Malakanundja II - discussed later) and places of environmental value. Key cultural information relating to past activities, and keystone plant species observed along the trails and at the sites was gathered during consultation. The opportunity was taken to perform short flora and fauna surveys along these transects, while archaeological surveys across larger areas of the lease have been undertaken in accordance with the mining company's Cultural Heritage Management Plan. 
All information was then recorded into a database and a geographical information system. Integration with historical records permitted the construction of detailed cultural maps and an analysis of historical and cultural activities. By grouping and viewing the intersections of various land use activities, it was possible to determine the broad pattern of broad cultural activity as well as more specific cultural attributes over localised areas. This is an iterative process of consultation, and further iterations are required before final conclusions can be drawn.

\section{Results}

The search of archives resulted in numerous maps and records of site locations, with detailed anthropological information related to movements of people and cultural activities becoming available. Many of the rock shelters contain significant galleries of cultural and ecological information, and photographs spanning a period of over thirty years allowed "baselines" to be determined and the extent of environmental impacts over the period of mining to be assessed. It is thought that species of fauna represented in rock-art from the wider region have totemic cultural significance and are representative of Binin hunting activities. Where identified, these species have been designated and incorporated into a list of keystone cultural species, examples of which are provided in Table 1.

The flora and fauna survey identified a number of contemporary floral keystone cultural species that appear to be widely distributed across Arnhem Land. Archaeological surveys identified a handful of scarred trees, a large number of small background scatters of stone implements and several quartz outcrops on the lease that show evidence of knapping and grinding. The quarrying on these outcrops is consistent with that observed at other outcrops and bluffs to the north of the lease.

The combined data point to a lengthy period of intense activity over the leased area and its immediate surrounds. They imply that specific cultural activities, not necessarily related to major ceremonies, were undertaken at a diverse number of locations across the lease. These are indicated in Figure 1. By linking these physical and historical observations with contemporary consultation, the broad pre-mining land use of the Ranger mining lease was identified as one consistent with hunting, gathering and foraging.

Table 1 Examples of keystone cultural species of the Ranger mining lease

\begin{tabular}{|c|c|c|c|}
\hline $\begin{array}{l}\text { Common } \\
\text { Name }\end{array}$ & Latin Name & $\begin{array}{l}\text { Erre/Urninajk } \\
\text { Language Name }\end{array}$ & Typical Cultural Value \\
\hline Sand Palm & Livistonia humilis & Angulalurrudj & $\begin{array}{l}\text { A slender palm with small yellow } \\
\text { flowers on long spikes. Used } \\
\text { extensively for medicine, dyes, fibre } \\
\text { and food. }\end{array}$ \\
\hline Ironwood & $\begin{array}{l}\text { Eucalyptus } \\
\text { squamosa }\end{array}$ & Arlanyunk & $\begin{array}{l}\text { Tall hardwood tree used for basic } \\
\text { tools. The trees were also considered to } \\
\text { be an important source of wild honey. }\end{array}$ \\
\hline Barramundi & Lates calcarifer & Madjinbalk & $\begin{array}{l}\text { Freshwater and saltwater fish used for } \\
\text { food. An important totemic species for } \\
\text { many clan groups. }\end{array}$ \\
\hline Wallaby & Macropus agilis & Ibak/Urrulamb & $\begin{array}{l}\text { Principal source of meat and furs. } \\
\text { Totemic animal with spiritual } \\
\text { significance. }\end{array}$ \\
\hline Bandicoot & Isoodon spp. & Karndidjbal & $\begin{array}{l}\text { Source of meat and furs. Totemic } \\
\text { animal with spiritual significance. }\end{array}$ \\
\hline
\end{tabular}




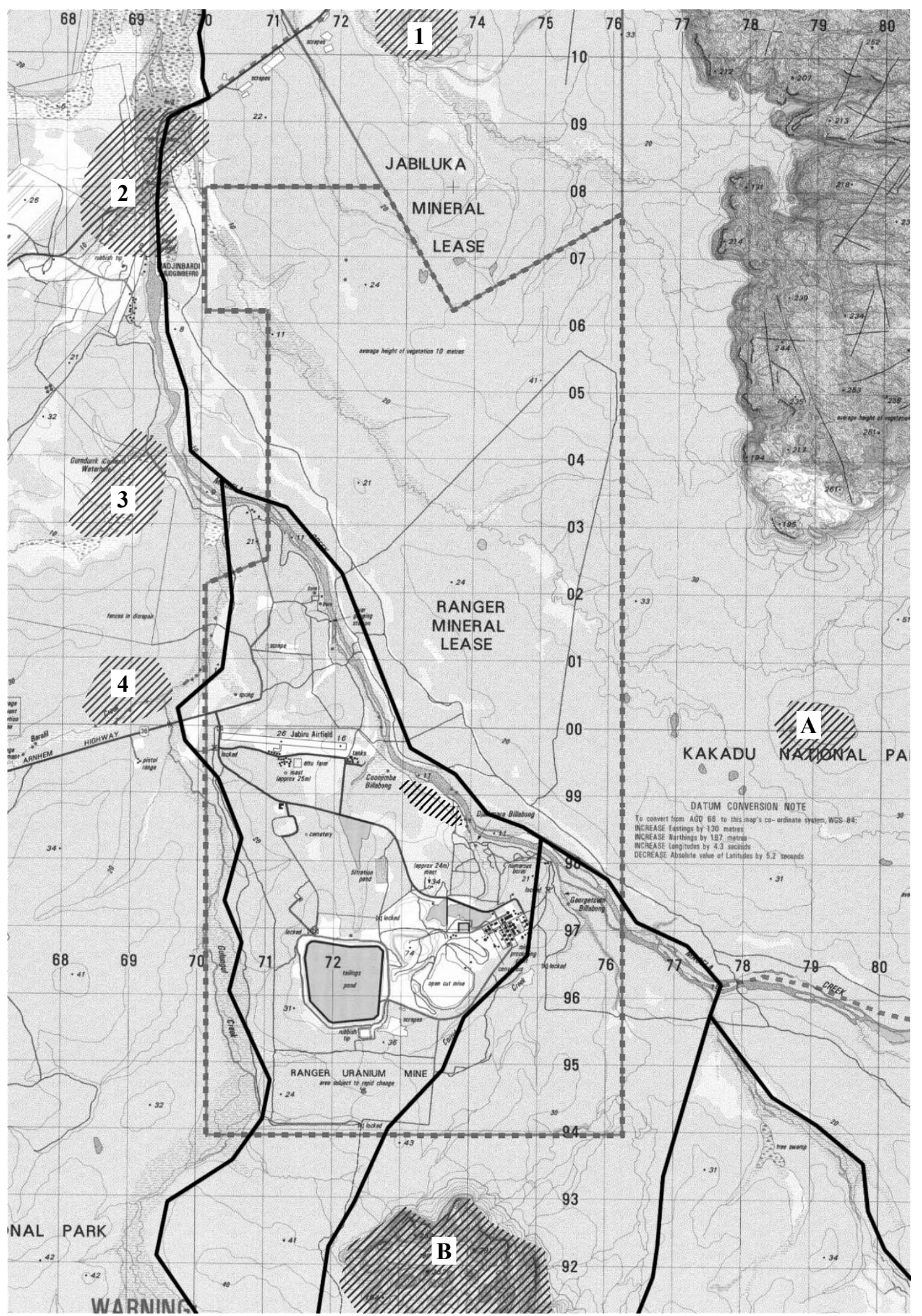

Figure 1 Cultural map of Ranger mining lease in context with the immediate Kakadu environment. The entire area depicted by the map was generally used for hunting, gathering and foraging. Sites of spiritual significance are labelled alphabetically, camping areas numbered and cultural activities in black hatching, while permanent walking trails are shown as solid lines 


\section{Discussion}

Articulation of specific cultural attributes of the cultural landscape that incorporates the mining lease is difficult, because of the need to consider the complex interactions between the individual components within the context of a holistic environment. Binin society recognises there is a fundamental symbiosis between spiritual beliefs, culture and ecology which did not develop slowly over time, but came simultaneously into existence during 'Nayuhynggi', a period of creation when:

\section{"The landscape and its features were left by the Creation Ancestors. They instituted and created ceremonies, rules to live by, laws, plants, animals and people, then they turned into djang (dreaming places and their spiritual essence). They taught Aboriginal people how to live with the land. From then on Aboriginal people became keepers of their country." (Parks Australia North, 2007)}

This is a theme common to Aboriginal societies throughout Australia (Barber and Rumley, 2003; McDonald et al., 2005) and one that briefly touches upon a close kinship with the environment. It is fundamentally different to Eurocentric views based upon evolutionary theory but perhaps more applicable because over thousands of years it has led to the development of practical environmental management systems that are ideally suited to sustainability of their local environments, and a keen understanding of what specific and local ecologies have to offer.

The key cultural attribute of Binin society involved exploitation of natural resources and in a manner similar to their social system, plants and animals belong to specific moieties ('dhuwa' and 'yirritja'). The overall environmental health of the land is dictated by the distribution and the balance between 'dhuwa' and 'yirritja' plants. A balance is essential because each has half of the total spiritual essence and purpose and it is through their combination that land achieves its harmony. Being linked with ceremonies and spirits, each also has a specific cultural role to play and their loss from any part of the environment results in a loss to culture. Many of these are the keystone cultural species that assume iconic or totemic standing, and feature prominently in the language, ceremonies, and narratives and underpin the social fabric because they play fundamental roles in diet, as materials, or in medicine (Garibaldi and Turner, 2004).

Closure criteria for keystone cultural plant species could conceivably be based around ecological criteria, on factors like abundance and distribution within the landscape and the capacity to develop self-sustaining populations. Specific criteria based on these factors have been proposed for Nabarlek but similar criteria are yet to be developed for the Ranger mining lease, where considerable effort is still required to develop accurate maps of 'dhuwa' and 'yirritja' locations on the lease to ensure that plant distributions blend in properly with the wider cultural landscape of Kakadu National Park. This will be difficult for the operational areas of the Ranger Mine because these areas have suffered the greatest damage, the cultural landscape has been destroyed and specific ecological information lost.

Exploitation of resources by Binin was generally opportunistic and dependent upon the periodic availability of specific flora and fauna. The major walking trails that covered the lease followed watercourses, and camping places were sited at locations where there was permanent fresh water. At one particular ridge along the Magela Creek there are numerous ironwood trees and quarried quartz outcrops that highlight an area previously used for prolific production of wild honey and quartz flakes. However, with access to the leased areas now restricted, regular visitation no longer occurs and the local environment has changed appreciably. The strand of ironwood no longer produces saplings, but the reason why has yet to be identified. It is clear though that steps need to be taken to reverse the situation or the cultural value of this location may be irretrievably lost.

The link between human movement across the landscape and distribution of flora and fauna leads to recognition of a second important criterion - access. Hunting, gathering and foraging requires wide ranging access across a number of different landscape units, with the watercourses and riparian units the most important. These are the most fertile areas and provide habitats suitable for a wide range of keystone species and are still in use today. Along these routes advantage was taken of intermittent quartz outcrops to fashion tools and other implements, so it is no coincidence that they also contain the major walking trails that link ceremonial and habitation sites in Binin society. 
Although there are a number of trails that cross the Ranger lease, there are few recorded sacred sites on the lease, although at least one burial site is known. This implies that other than burial rites, major ceremonies were not generally performed in areas in the immediate vicinity of the mine. This is supported by extant verbal information indicating major ceremonies were generally undertaken at important sites to the north and to the south of the current mining lease. Of these sites, one of the most valuable is Malakanundja II, which has levels of occupation dating back 50-60,000 years (Roberts et al., 1998), whilst also containing examples of contact artwork from the modern era. Although the entrance is now badly infested by weeds, this site remains an important part of the Aboriginal cultural landscape.

At Ranger, direct perturbation of the walking trails has been minimal, but access to a large area of land, over 500 ha consumed by operational and associated areas, has been lost. In consequence, traditional land management practices are no longer performed and although access to much of the land will ultimately be restored, the radioactive nature of mining waste means that long-term restrictions on specific activities may need to be put into place over some parts of the surrendered lease. Free access will be hindered by the size and amount of waste rock that is left on the surface, while the drawing of groundwater from some specific locations will be prohibited because of the risk of radioactive contamination. Beneficial use of natural and man-made sentinel waterways for gathering of food will be restricted by residual radiation flux and chemical contamination.

Restrictions that are placed on harvesting specific keystone cultural species from locations such as the rehabilitated pits remain unknown until the risk of contamination has been scientifically assessed, so it may be appropriate to use a measure of this risk as a scientific means of assessing the return of this aspect of cultural activity. If safe collection and use of resources from those areas cannot be guaranteed, then traditional practices in that area will remain dysfunctional and future value of the land diminished long into the future. Should this occur, it could be argued that the required cultural and environmental attributes applied to Kakadu had been fully met, so a closure certificate could not be issued without further work to address the deficiencies.

It may also be possible to use a measure of the amount of land that has been returned in a state commensurate with continuation of the pre-mining land use patterns, backed up by physical measurements related to parameters such as the ease by which people can travel across the reconstructed landform to reach specific natural resources or areas of ceremonial or resource significance. This could be a relatively easy process as the amount of land affected by operations can be directly measured. The difficult part of producing a measurable criterion would then remain in the subjective assessment of how the physical state of the returned land's surface was interpreted in terms of 'ease of access'.

So far, only physical factors, related to distinct environmental measures have been discussed. Another facet of Aboriginal culture that cannot be considered objectively, but must be addressed is its spiritual heritage. Ecological factors that can be measured for keystone cultural species having mythological or spiritual values will provide part of the answer, but other intangible factors that describe the fundamental belief systems of Binin culture do not have a comparable system of measurement. How Binin perceive and understand the movement of spirit beings through the environment is alien to the European mind, and cannot be measured in physical terms, so for this, a series of indices are proposed.

In Binin language, 'djang' describes both a sacred place and the energy it holds. This energy permeates the entire landscape and is recharged or defused by ceremonial activity. Where the energy is negative, e.g. at a dangerous sacred area, it is known as 'djang andjamun' and the area is avoided as much as possible. Near the Ranger uranium lease, the most troublesome 'djang andjamun' is at 'Djibidjibi' (Mount Brockman), less than two kilometres distant. The strength of 'djang andjamun' related to 'Djibidjibi' is of considerable concern to Binin because it carries north across much of the lease. Any significant disturbance, such as mining, in closer proximity of 'Djibidjibi' carries with it the risk of illness and death so the site must be watched very carefully.

Although physical criteria related to the reconstructed landform have already been suggested (Smith, 2008), an index that establishes Binin satisfaction or degree of comfort with the outcome has yet to be formulated. A need for similar indices applies to access and to some specific environmental matters such as water quality and resource availability. However, these cannot be constructed until scientifically verifiable data for plant abundance, species distribution and risk assessments have first been compiled. 
Ideally, cultural closure criteria and measuring indices developed must have wider application than just the Ranger uranium mine. Figure 1 shows that the broad cultural landscape of the Ranger lease is relatively simple, although a special focus is required on a number of highly localised areas. However, the cultural landscapes of other nearby mining leases are more complex because of their higher level of archaeological heritage, anthropological heritage and ceremonial function. To the north, rock art and archaeological sites are abundant and continue to have significance because a strong association still exists between them and living traditions and beliefs. In scientific terms, they also represent useful locations where detrimental impacts to cultural objects and ecological health can be monitored simultaneously. For these, an index of site preservation, based upon the degree of deterioration of artwork and general aspects of the site, which includes a measure of the ecology, has been generated.

Table 2 Guide for proposed cultural closure criteria for mine sites based upon evidence gathered from the Ranger uranium mine

\begin{tabular}{|c|c|c|c|}
\hline Attribute & $\begin{array}{l}\text { Role in Cultural } \\
\text { Landscape }\end{array}$ & $\begin{array}{l}\text { Proposed "Indigenous" } \\
\text { Criteria }\end{array}$ & $\begin{array}{l}\text { Scientific Criteria } \\
\text { Derived from Ecology }\end{array}$ \\
\hline $\begin{array}{l}\text { Spiritual heritage - belief } \\
\text { systems }\end{array}$ & $\begin{array}{l}\text { Provides a fundamental } \\
\text { understanding of } \\
\text { cosmology and reason } \\
\text { and links the individual } \\
\text { parts of the landscape } \\
\text { together. }\end{array}$ & & \\
\hline \multirow[t]{3}{*}{$\begin{array}{l}\text { Archaeological heritage } \\
\text { - rock art }\end{array}$} & $\begin{array}{l}\text { Manifestation of } \\
\text { mythology and spiritual } \\
\text { beliefs. }\end{array}$ & $\begin{array}{l}\text { Index of site } \\
\text { preservation. }\end{array}$ & $\begin{array}{l}\text { Physical characteristics } \\
\text { of the land surface. }\end{array}$ \\
\hline & $\begin{array}{l}\text { Transmission of } \\
\text { knowledge and history } \\
\text { over generations. }\end{array}$ & & $\begin{array}{l}\text { Landform characteristics } \\
\text { and general aesthetics. }\end{array}$ \\
\hline & $\begin{array}{l}\text { Indications of habitation } \\
\text { and ceremony. }\end{array}$ & Index of accessibility. & \\
\hline \multirow{3}{*}{$\begin{array}{l}\text { Anthropological heritage } \\
\text { - ceremonial activities }\end{array}$} & Transmission of & Index of accessibility. & \\
\hline & knowledge and history. & $\begin{array}{l}\text { Level of ongoing } \\
\text { practice. }\end{array}$ & \\
\hline & & $\begin{array}{l}\text { Index of site } \\
\text { preservation. }\end{array}$ & \\
\hline \multirow[t]{7}{*}{ Traditional use } & $\begin{array}{l}\text { Hunting, gathering and } \\
\text { foraging: }\end{array}$ & Index of accessibility. & \\
\hline & - Foods. & & Abundance. \\
\hline & - Medicines. & & Patterns of distribution. \\
\hline & - Clothing. & & Concentration of weeds. \\
\hline & - Tools. & & Chemical toxicity. \\
\hline & - Water. & & Index of water health. \\
\hline & $\begin{array}{l}\text { Other highly localised } \\
\text { land use patterns. }\end{array}$ & & $\begin{array}{l}\text { Index of ecological } \\
\text { health. }\end{array}$ \\
\hline
\end{tabular}


The quality of photographic baseline information that is available for many of these sites is high which allowed an assessment of current conditions to the pre-mining environment to be made. Given the variety of other environmental vectors, e.g. feral animals, tourism and mining, that have influenced this area over the past century, it is difficult to allocate a specific degree of deterioration to any given activity. For sites like these that may have confounding influences from a variety of vectors, it may often not be possible to develop general rules, suggesting that closure criteria for culturally significant sites will need to be developed on a site specific basis.

These criteria need to include components related to ecology and distribution of plant species, ease of access, and general aesthetics, which includes a subjective measure of the level of comfort held by people visiting the site. Of these, matters related to access of the site are considered the most important because without access, required cultural activities, e.g. performance of rituals, will not occur. Recognising that these criteria need to be considered and obtained long before mining occurs, the Northern Land Council routinely undertakes cultural heritage clearances during the exploration phase on Aboriginal freehold land. Recently this has been expanded in the northeast Arnhem Land region to include highly localised flora and fauna surveys that are now being interpreted in terms of traditional ecological knowledge, cultural land use patterns, and mythology in the context of the broader cultural landscape. The information is placed into a cohesive format that is being used to develop meaningful criteria and end land use objectives addressing all stakeholders' concerns in an equitable manner. From this, baseline cultural landscapes that are more comprehensive than that determined for the Ranger Mine are being developed.

Conversely, at Ranger, the cultural landscape is determined by the World Heritage listing. An interpretation of the cultural attributes for which Kakadu National Park was inscribed upon the World Heritage register is listed in Table 2. The relationship to the overall cultural landscape and to relevant scientific criteria and indices of measurement that has come from this work is demonstrated, and it is recommended that these be applied to all mining related activity in the region. However, it is fair to say that at the moment, formal measures for many of these need to be finalised or agreed between all stakeholders. A number of important ideas have been generated, but further consultations and information are required before they can be put into practice. The indices that have been prepared need further testing but once this is completed, practical, robust and measurable closure criteria that are to the satisfaction of the Aboriginal custodians of the land and which meet the commonwealth government's environmental requirements will become available.

\section{Conclusions}

Collectively, historic knowledge and Aboriginal mythology provide context, cultural value and significance to each specific location identified within any mining lease. Provided this knowledge is available, then a description of cultural attributes and the cultural landscape becomes possible. It is only when there is a considerable amount of detail available that the cultural landscape can be adequately defined and that credible cultural closure criteria can be developed.

In this context, the broad pre-mining Aboriginal land use on the Ranger mineral is defined as one consistent with hunting, gathering and foraging; to which ecology identical to that of the pre-mining environment is best attuned. The defined land use is commensurate with the environmental requirements, and with the values ascribed in the Environmental Protection and Biodiversity Conservation Act, the Aboriginal Land Rights Act and the Park leases, all of which provide for continued traditional (cultural) use of natural resources within Kakadu National Park. Highly localised deviations exist in some small areas, and it is the expectation of the land owners that specific cultural closure criteria for these areas will be developed. These are to be consistent with the wider context of the overall cultural attributes assigned to Kakadu National Park and endorsed by the World Heritage Commission.

By integrating a mix of scientifically justified ecological measures and interpretive cultural indices, an acceptable system of measurable cultural criteria can be developed. The success of these will be entirely dependent on the contents of the indices, the level of baseline information available and the demonstrated links between belief systems, cultural activities and the scientific measures. In consequence, the process works best where high quality eco-cultural information is obtained before the mining phase begins, but can still be useful if culture has remained strong and the knowledge base is more or less intact. 
Even at Ranger, where the immediately affected landscape is not overly complicated by the presence of spiritually important sites, full development of measurable closure criteria acceptable to the land owners, the mining company and the federal and Northern Territory regulators still appears to be well into the future. Indigenous people expect that ecological components based around specific keystone cultural species will play an important role, as will the consideration of specific cultural values related to landform and water. They remain confident that these expectations will be met, and that in time a formal system of assessment based upon traditional ecological and cultural values will be developed and applied across all phases of mining activity. Indigenous people argue that only then will we have a system that can truly be called world's best practice.

\section{Acknowledgements}

The author acknowledges the wealth of information, the support and encouragement that has been provided graciously and freely by the Mirarr Gunjeihmi - traditional custodians and owners of the lands affected by the Ranger uranium mine; and by their corporation's scientific consultant Geoffrey Kyle and chief executive officer Justin O’Brien.

\section{References}

Barber, K. and Rumley, H. (2003) Gunanurang: (Kununurra) Big River Aboriginal Cultural Values of the Ord River and Wetlands, A Study and Report Prepared for the Water and Rivers Commission, Perth, Western Australia.

Department of the Environment, Water, Heritage and the Arts (DEWHA) (1999) Environmental Requirements of the Commonwealth of Australia for the Operation of Ranger Uranium Mine, Department of the Environment, Water, Heritage and the Arts, Commonwealth of Australia, Canberra.

EWL Sciences Pty Ltd (2006) Energy Resources of Australia Ranger Mine final landform design: Stakeholder workshop, 2 December 2005, Internal Report 5, February, Supervising Scientist, Darwin, Unpublished paper.

Garibaldi, A. and Turner, N. (2004) Cultural Keystone Species: Implications for Ecological Conservation and Restoration; Ecology and Society online, Vol. 9(3), pp. 1-18.

Glen, E. and Smith, H.D. (2006) Science, Traditional Environmental Knowledge and Mining in the Alligator Rivers Region, Northern Territory, Australia, 17th Alligator Rivers Region Technical Committee Meeting, 27-28 February 2006, Darwin, Australia, Unpublished paper.

Hancock, G.R., Evans, K.G., Willgoose, G.R., Moliere, D.R., Saynor, M.J. and Loch, R.J. (2000) Medium-term erosion simulation of an abandoned minesite using the SIBERIA landscape evolution model, Australian Journal of Soil Research, Vol. 38(2), pp. 249-264.

Hollingsworth, I. and Lowry, J. (2005) Landscape reconstruction at the Ranger Mine, In Proceedings of the North Australian Remote Sensing and GIS Conference, NARGIS 2005, 4-7 July 2005, Darwin, Applications in Tropical Spatial Science (CD-rom).

McDonald, E., Coldrick, B. and Villiers, B.A. (2005) Study of groundwater-related Aboriginal cultural values on the Gnangara Mound, Western Australia, Estill and Associates, Report to the Department of Environment, Perth, Western Australia.

Parks Australia North (2007) Kakadu National Park: Management Plan 2007-2014, Parks Australia North, Commonwealth of Australia, Darwin.

Roberts, R., Yoshida, H., Galbraith, R., Laslett, G., Jones, R. and Smith, M. (1998) Single-aliquot and single-grain optical dating confirm luminesence age estimates at Malakunanja II rock shelter in northern Australia, Ancient TL, Vol. 16(1), pp. 19-24.

Smith, H.D. (2008) Using traditional ecological knowledge to develop closure criteria in tropical Australia, In Proceedings of the Third International Seminar on Mine Closure, Mine Closure 2008, A.B. Fourie, M. Tibbett, I.M. Weiersbye, P. Dye (eds), 14-17 October 2008, Johannesburg, South Africa, Australian Centre for Geomechanics, Perth, pp. 47-56.

United Nations Educational, Scientific and Cultural Organisation (UNESCO) (2008) Operational Guidelines for the Implementation of the World Heritage Convention, United Nations Educational, Scientific and Cultural Organisation Intergovernmental Committee for the Protection of the World Cultural and Natural Heritage, Paris, France, pp. 14-15. 